\title{
LA EVANGELIZACIÓN EN EL HORIZONTE DEL DESIGNIO SALVIFICO UNIVERSAL
}

Luis Martinez S.

En este articulo he querido ordenar algunas ideas sobre cómo y cuál debe ser la actitud de los que nos llamamos discipulos de Jesús para que nuestro testimonio del Evangelio sea hoy una Buena Noticia de Salvación. Se trata de replantearnos el sentido y el estilo de la evangelización, tomando en cuenta los nuevos acontecimientos y dinámicas que atraviesan el mundo contemporáneo, pues es alli, para estos hombres y en esta historia concreta, que el anuncio de Jesucristo Saivador debe ser buena noticia. Un objetivo subordinado de este escrito es hacer una invitación a adoptar una actitud más abierta. más universal y tolerante desde la cual confesar nuestra fe en un mundo lleno de novedades y desafios.

\section{A. Evangelización Y Seguimiento de Cristo}

"Vayan a las gentes de todas las naciones y háganlas mis discipulos; bauticenlas en el nombre del Padre y del Hijo y del Espiritu Santo. y enseñenles a guardar todo lo que les he mandado a ustedes. Yo estare con ustedes todos los dias y hasta el fin del mundo" (Mt 28,19).

La lectura atenta de Mateo 28, 19 sugiere una serie de pautas de gran actualidad para la evangelización en el mundo actual. En efecto, el paradigma evangelizador alli presente avanza del encuentro con "las gentes de todas las naciones" al anuncio de la presencia salvifica de Dios con ellos. En este proceso la comunidad, más que enseñar doctrinas, da testimonio con su vida de la presencia del Reino y anuncia su realización escatológica. Sigamos paso a paso el texto:

La invitacion: "Vayan a las gentes de todas las naciones y háganlas mis discipulos" implica, necesariamente, un movimiento previo de acercamiento y simpatia con el mundo según el estilo de Jesús. Se trata de encontrarse con esas gentes, de amarlos y respetarlos, de esforzarnos por 
conocer sus dificultades y sus sueños, su lenguaje y sus imaginarios culturales; conocer todo aquello que nos permita crear puentes que nos permitan comunicar nuestra experiencia creyente en sus propias categorias, de tal modo que el anuncio del Dios Trinidad sea una verdadera Buena Noticia para ellos.

En seguida, la fórmula ternaria única en los evangelios: "Bauticenlas en el nombre del Padre y del Hijo y del Espiritu Santo, es fundamentalmente un anuncio de la presencia salvifica de nuestro Dios a través de toda la historia de la humanidad, acompañando a cada individuo y a cada pueblo en su búsqueda de vida plena. Esta fórmula nos invita a mostrarles el verdadero rostro del Dios de los cristianos, el que se nos manifestó como un Padre misericordioso que envió a su Hijo para compartir nuestra historia y revelarnos la profundidad de su Designio de vida para nosotros, y que nos sostiene por la fuerza de su Espiritu Santificador y dador de vida desde la creación hasta la consumación de la historia.

Por su parte, la exhortación: "enseñenles a guardar todo lo que les he mandado a ustedes", se refiere más que a la enseñanza de un cúmulo de doctrinas morales, a dar testimonio, a enseñar en el sentido de mostrar por medio de una práctica consecuente con los dichos y actos de Jesús de Nazaret, que el Reino de Dios es de los pobres, de los que luchan y son perseguidos por causa de la justicia. Es acoger como comunidades el desafio de las bienaventuranzas, transformándonos en servidores y heraldos de la única voluntad salvifica de Dios que se despliega por todo el universo.

Esta gran tarea evangelizadora obtiene todo su dinamismo de la certeza que debe tener la comunidad cristiana de la presencia del Señor resucitado a su lado: "Yo cstaré con ustedes todos los dias y hasta el fin del mundo". Es una presencia activa, que apunta a la realización del proyecto que Dios tiene para el mundo. Desde la perspectiva escatológica de los evangelios, debe entenderse "el fin del mundo" como el nacimiento de la humanidad definitiva que hoy se encuentra en pleno trabajo de parto, con dolores e incertidumbres, pero con la esperanza de la vida nueva que está por nacer, y al cual los cristianos deben asistir activamente cual equipo de parto comprometido con la marcha de la historia humana hacia su plenitud (cfr Mc 13,8).

\section{B. Notas sobre los tiempos que vivimos.}

Ciertamente una gran novedad del Concilio Vaticano II fue su invitación a cambiar nuestra mirada y asumir con gozo la conciencia cristiana de la acción del Espiritu en el mundo acompañando la historia de todas las naciones hacia su consumación (Cfr GS 4, 11). Con ello, el Concilio abrió un camino nuevo para la evangelización, que alejándose del proselitismo. se comprende más como un aporte fraterno en la búsqueda de la comprensión de las grandes interrogantes de la humanidad. En efecto, esta toma de conciencia de la presencia del Espiritu en los acontecimientos 
históricos autónomos, no necesariamente situados al interior de las fronteras visibles de la Iglesia institucional, nos obliga hoy como comunidad cristiana a escrutar en el pulso de los acontecimientos de la humanidad, la voz del Señor de la historia que nos interpela desde el avance o los obstáculos que encuentra su Designio salvador. Se trata de una lectura espiritual de la historia, que nos permite mejor comprender y adaptar la única $\mathrm{Fe}$ a la situación actual, pues la fidelidad al Espiritu, implica prestar atención a toda la historia humana como verdadero lugar teológico en donde Dios se nos manifiesta llevando adelante la realización de su Proyecto salvífico para todos los hombres y por caminos que sólo él conoce.

Acoger esta nueva perspectiva que nos propuso el Concilio, internalizando la radicalidad de dicha afirmación, resultará fundamental para avanzar hacia una comunidad cristiana que se autocomprenda como una Iglesia al servicio del Designio Salvífico de Dios que se despliega por todo el cosmos. Al mismo tiempo, la comunidad evangelizadora en diálogo con el mundo, abierta hacia él con optimismo, tratando de descubrir alli las huellas de esa presencia y comprometiéndose con la historia que avanza hacia su consumación, verá que se abren ante sus ojos nuevos horizontes de comunión y encuentro con aquellos que se encuentran lejos.

Por otra parte, si queremos que la evangelización como anuncio de la salvación querida y obrada por Dios a través del mundo entero desde la creación y hasta su consumación no sea "ni atemporal ni ahistórica", todo acto evangelizador debe, en consecuencia, partir de una mirada previa sobre la realidad actual y su proyección hacia los años venideros. La Iglesia al evangelizar debe ser capaz de contemplar los acontecimientos históricos. especialmente de la historia de los pobres, asumiéndolos como significativos para la fe. Por lo mismo, hemos querido comenzar estas reflexiones presentando grosso modo dos notas que consideramos caracteristicas de nuestra sociedad contemporánea y que, vistas como "signos del Espíritu en la historia" podrian ser de gran virtualidad para el despliegue de una acción evangelizadora con características nuevas de acuerdo al sentir del hombre y la mujer contemporáneos. La primera es la valoración creciente tanto del sujeto libre como de su espacio microsocial: y la segunda, el desafío que representa la globalización con sus consecuencias paradojales, de marginación y valorización de las identidades locales.

\section{Valoración del Sujeto Libre y del Espacio Microsocial}

En la actualidad, asistimos al nacimiento de una nueva época, en la que se conjugan las grandes opciones macrosociales de la globalización económica con estructuras microsociales de gran libertad y creatividad. Los individuos no están más dispuestos a dejarse "enrolar" en entidades partidos politicos, sindicatos, religiones, etc.- que coarten su libertad fundamental. Por el contrario, los hombres y mujeres de nuestra sociedad contemporánea recuperan y ejercen su protagonismo en los espacios microsociales. La vida en sociedad, con sus obligaciones de trabajo, de 
consumo y de respeto a la legalidad se asume sólo como mal menor, que posibilita el acceso a espacios microsociales donde todo puede ser reinventado o reconquistado por el individuo que ya no se contenta con ser un "idiota cultuar" (Coulon). El hombre de hoy no acepta ser sólo un ente pasivo, condenado a la repetición fatal de una doctrina o de un habitus impuesto por el grupo, tampoco acepta ser un mero realizador de proyectos ajenos. El se siente y quiere ser protagonista de la historia que lo rodea. pues valoriza su libertad. Su conciencia autonoma con sus opciones personales de sentido y de acción.

En este nuevo paradigma. la verdad, los valores el sentido. la fe. etc.. se comprenden como categorias relativas y en constante evolucion. La búsqueda de la verdad, por ejemplo, se percibe hoy como una verdadera curva asintótica -como algo que solo podra ser alcanzado en el infinitodejando de ser un bien pre-adquirido o preestablecido con exactitud por ninguna doctrina. Otra caracteristica de la "verdad" contemporánea es su carácter fundamentalmente fragmentario. esto es. como fruto de diversas visiones complementarias que se unen para formar una verdad que sobrepasa a los individuos, a los grupos, a las culturas y a las religiones. En este terreno ya no hay más lugar para visiones con pretensiones monoliticas y totalitarias sobre el hombre y el mundo. En este mismo sentido. la racionalidad se comprende, hoy en dia. como un modo de conocer poco a poco -por "ración"-. por lo que lo razonable ha llegado a ser sinónimo de pluralismo y tolerancia. sobre todo con la valoracion de lo interdisciplinar. Es decir, la racionalidad se ha transformado en la capacidad de llegar a consensos que respeten y permitan el desarrollo de lo diverso sin aferrarse ni a moldes preconcebidos ni a visiones parciales de la realidad.

Basta con dar una mirada rapida a la sociedad actual, especialmente a los jóvenes, para descubrir alli un fenomono creciente en medio de ella: grupos importantes optan. claramente. por forjar nuevos espacios microsociales caracterizados por una critica y una actitud antisistemica. Son sub-grupos criticos al sistema cultural, politico y económico que se impone desde la globalizacion y que buscan recobrar su protagonismo alienado en y por las estructuras sociales que ellos han heredado y de las cuales no se sienten ni responsables ni solidarios. Sin cerrarse al mundo de lo valórico. exigen ser convencidos sobre la pertinencia de una norma antos de acatarla El hombre y la mujer de esta nueva época ya no aieptan la intromisión heteronoma de la ley, sino que quieren vivir lo valorico desde la autonomia personal. No se trata de una negacion a toda positilidad de exterioridad moral. sino de una nueva manera de entender la norma. sea esta social o religiosa, como fruto de una asunción personal fundada. De lo contrario, ella es sentida como arbitraria y opresiva

Por otra parte. y para no caer en un simple dualismo nostálgico del pasado, es necesario agregar que si bien es cierto que el hombre de hoy busca la verdad y la razón primeramente a partir de si mismo y de lo microsocial, con el riego subyacente de la tautologia o del solipsismo, el 
recurso a la alteridad -sea ésta el "otro" individuo, la "otra" cultura o el "Otro" Dios- sigue siendo relevante, sobre todo con el avance vertiginoso de los medios de comunicación y de transporte que van forjando un mundo cada vez menos aislado. Asi, y casi paradojalmente, en esta misma sociedad occidental marcada fuertemente por el individualismo y las actitudes narcisistas, surgen experiencias de solidaridad organizada o de colaboración filantrópica, crece también la conciencia ecológica y las ganas de conocer y comulgar con la diferencia a niveles nacionales e internacionales.

\section{La Instauración de un Mundo Globalizado y Dual}

Como segunda nota, no podriamos dejar de mencionar aquella que a los ojos de la mayoria es la caracteristica sobresaliente del mundo contemporáneo. Nos referimos, evidentemente, a la "globalización" o la irrupción en la historia contemporánea de un sistema mundial que marca el término de una etapa de la humanidad que surgió con el nacimiento de las repúblicas, y que se estructuraba sobre los estados nacionales o, posteriormente, en torno a grandes bloques ideológicos. En el último tiempo, progresivamente las sociedades, naciones y estados han perdido autonomia y se han ido integrando en un mundo intercomunicado por el desarrollo de los medios de transporte y comunicación, en pos del intercambio de la producción, el comercio y las finanzas. Este fenómeno mayor de nuestra época, apunta a hacer del mundo una "gran aldea", interrelacionada fundamentalmente por el sistema económico neoliberal.

Los capitales transnacionales son los verdaderos gobernantes de las naciones; sus directivas restringen todo margen de acción a los gobiernos locales, los que se ven obligados a endeudarse con ellos, y a desregularizar los mecanismos de protección de las economias locales para permitir el flujo libre del capital, aunque ello signifique desproteger a los sectores más débiles de la sociedad. Por la influencia del capital, los modos de producción han cambiado, sobre todo con la incorporación de la informática, la robótica, la genética y la competencia por la conquista de nuevos mercados, todo lo cual genera al mismo tiempo marcos de incertidumbre e inestabilidad en las economias locales. En todo caso, y a pesar de las criticas al sistema que se van imponiendo, sobretodo por su insensibilidad respecto de los pobres y marginados, la globalización aparece como un fenómeno inevitable en el que, querámoslo o no, estamos atrapados y cuyo impacto se hace creciente en todas las realidades de la vida actual.

La emergencia de esta nueva era de la humanidad puede ser vista desde aspectos positivos: mayor conciencia de los procesos mundiales, mayor participación en los eventos planetarios, mayor capacidad de organización y vinculación, una creciente conciencia de "universalidad" que nos lleva a superar sectarismos y nacionalismos etnocéntricos, etc. Sin embargo, hoy en dia se hace cada vez más evidente que la nota que mejor caracteriza el fenómeno resulta ser, paradojalmente, la exclusión. La asi llamada igualdad frente al mercado no es tal. Sólo algunos tienen acceso real 
a él: en cambio grandes sectores de la humanidad permanecen al margen del consumo y de los progresos de la sociedad moderna.

De hecho. más que de "globalización" algunos prefieren hablar de "dualización", pues. en realidad. se está gestando una estructura mundial clara y dramáticamente "dual", donde unos pocos se enriquecen a costa de la explotación y el olvido de muchos: aumenta la miseria, el desempleo, la exclusión de muchos... mientras crecen las fortunas de los poderosos y se concentran los capitales y el poder en unos pocos. La brecha entre ricos y pobres en lugar de disminuir se acrecienta. Sỏlo en los últimos treinta años, la participación en el ingreso mundial del $20 \%$ más pobre de nuestro planeta se redujo de $2,3 \%$ a un $1,4 \%$ y en contrapartida. el $20 \%$ más rico aumentó sus ingresos de $70 \%$ a $85 \%$; al extremo que en si 1996. 358 personas supermillonarias -de las cuales cuatro son chilenas-acumulaban el $47 \%$ de la riqueza mundial. en el año 2000, sólo seis personas supermillonarias acumulaban el $57 \%$ de la riqueza mundial. Otro ejemplo. si el año 1996 en América latina 86 millones de personas ( $18 \%$ de la poblacion) se encontraban en condiciones de extrema pobreza, se calcula que para el 2005 habrá 176 millones en las mismas o peores condiciones.

Dentro de esta inmensa masa de empobrecidos y marginados. no puedo dejar de mencionar al Pueblo Mapuche, que por io demás corre la misma suerte que otras etnias originarias en el continente. Resulta significativo que las comunas más pobres del pais. sean todas de fuerte presencia Mapuche, los que podrian ser considerados segun el decir de Puebla como "los mas pobres entre los pobres". La pobreza que tos aflige no les es esencial como pueblo -como algunos lo piensan-, sino que es producto de la negación de su existencia como pueblo con identidad y cultura propias, y de la aplicación del sistema de economia neoliberal que promueve la globalización. De alli que hoy asistamos a un proceso de reivindicación que exige su reconocimiento como pueblo con la debida autonomia propia de su especificidad como etnia.

Esto nos da pie a recordar que la efervescencia tanto de los nacionalismos como de los integrismos religiosos. en algunos casos bastante cruentos, que vemos hoy son el signo de otra de las paradojas del actual paradigma mundial: una globalizacion que no ha sido capaz de responder adecuadamente a la existencia de la multiplicidad de identidades culturales. En efecto, la energencia tanto de los "nacionalismo" que han cambiado las fronteras conocidas hasta hace pocos años con la aparición de nuevos paises - por ejemplo, la cesesión de los paises bálticos (Lituania. Letonia y Estonia). el desmembramiento de la Yugoslavia de Tito (Croacia, Serbia, Eslovenia, Macedonia) y de la URSS (Rusia, Bielorusia, Ukrania. Georgia. Armenia, Azerbaiyan, Turkmenistam. Tadjastan. Ouzbekistan. Kasastán. etc) o las fuchas tribales entre Tutsis y Hutus de Ruanda y Burundi-: como la subida creciente del fundamentalismo islámico en paises como Argelia. Irán e Irak. Paquistán. Afganistán. etc.. muestran un cierto fracaso del proceso de globalización o unificación planetaria. La insatisfacción de grandes sectores de 
la humanidad ha llevado a la aparición de nuevos bloques diferenciados ya no por una cierta ideologia económica sino por sus referentes religiosos y culturales, lo que los hace aparecer como cada vez más irreconciliables.

Estas dos paradojas, la marginación y pobreza de grandes sectores de la humanidad asi como la incapacidad del actual sistema de resolver adecuadamente la relación entre cultura global e identidad y autonomía local, nos hacen percibir el actual sistema de globalización económica como un verdadero gigante con pies de barro. Para botón de muestra los acontecimientos en torno a los atentados del 11 de septiembre en New York $y$, en un nivel más local, la persistencia del conflicto mapuche.

\section{Buenas Noticias para el Hombre de hoy}

En consecuencia con el mandato de Jesús, preguntarse por la coherencia entre nuestras prácticas evangelizadoras con el seguimiento de Jesucristo y con el anuncio del reino como voluntad salvifica universal que se despliega por todo el cosmos, resulta de gran pertinencia y debe ser una actitud constante de cada cristiano, de cada comunidad y de la Iglesia toda. $Y$ ello no puede ser sino estando dispuestos a acoger los nuevos desafíos y las posibilidades de la nueva época que comienza a desplegarse ante nuestros ojos. Particularmente, si queremos que el anuncio de Jesucristo sea realmente una Buena Noticia para el hombre y la mujer de hoy, la evanyelización deberia hoy hacer un esfuerzo por renovarse en su lenguaje y en su estilo de presentación del mensaje cristiano sobre todo tomando en cuenta que el hombre de hoy, como lo acabamos de ver, es cada vez más refractario a la prepotencia y la intolerancia, sobre todo en aquello que toca los valores y las creencias. Di igual modo, si queremos que la evangelización sea realmente acogida como un mensaje salvador, el anuncio de la liberación de los pobres seguirá siendo la nota caracteristica de la salvación cristiana (cfr Lc 4, 18s), sobre todo en el actual proceso de dualización económica que vive la humanidad.

\section{El Nuevo Lenguaje de la Evangelización}

Como en todos los tiempos evangelizar conlleva un esfuerzo siempre necesario de diálogo entre la Fe que se quiere anunciar y la Razón o las razones del hombre contemporáneo. Este ejercicio no ha estado ajeno a la historia del cristianismo. Los Padres hicieron grandes esfuerzos por presentar la $\mathrm{Fe}$ a sus contemporáneos en las categorias que ellos vehiculaban, pues las reconocian capaces de Dios. Aún cuando se tenia conciencia de la precariedad e incapacidad de la razón humana por abarcar el misterio último de Dios, desde el principio encontramos en los símbolos de los grandes concilios la cooptación de conceptos filosóficos -como esencia, substancia, persona, etc.- para ayudar a los hombres de esos tiempos y culturas a alcanzar una mejor comprensión del dato revelado. La 
Fe nunca fue considerada ni una "arbitrariedad" ni una "irracionalidad", sino un logos a-logos, es decir, una razón que escapa a nuestra racionalidad, que la transgrede, pero que no la anula ni a desecha; de alli, el empleo en los Simbolos de palabras como "inefable", "incomprensible" o "misterio" para referirse a las verdades de la fe cristiana, que aunque escapan a los limites de la simple razón, no le son repugnantes.

En los sigios posteriores, serán los maestros de la escolástica quienes harán grandes esfuerzos por anunciar la fe en las categorias de sus contemporáneos -bástenos traer a la memoria a figuras como San Anselmo. Santo Tomás, San Buenaventura, Duns Scoto y tantos otros-. En nuestros tiempos, será el Concilio Vaticano II quien propiciará un retorno al diálogo con el mundo contemporáneo y sus razones. Haciendo recurso a nuevos y más adecuados instrumentos de comprensión de la realidad como la antropologia, la economia, la sociologia, etc- los discipulos del siglo XX y ahora XXI verán desplegarse ante sus ojos nuevas y originales perspectivas para la evangelización. En ella, los discipulos de aquel que vino a traer la vida en plenitud ( $\mathrm{Jn}$ 10,10) presentan fraternalmente a los hombres el camino verdadero que conduce hacia la verdad sobre el hombre y sobre el cosmos, es decir, hacia su vida definitiva (cfr Jn 14,6). No hay, entonces, verdadera evangelización si no se produce un real encuentro entre la razón o las razones humanas y la revelación (cfr FR n.23).

Por otra parte, la fe que no es razonada no es verdaderamente humana -porque excluye arbitrariamente la facultad critica de la inteligencia racional del ser humano- ni es verdaderamente fe, sino que se reduce a un cierto fideismo precientifico. La fe y el creyente como tal deben exponerse al juicio crítico de la razón democrática contemporánea, de otro modo su testimonio evangelizador no superaria al proselitismo fanático de las ideologias, cargado de arbitrariedad e intolerancia. La verdad que Dios nos ha revelado sobre si mismo y sobre el hombre, la hemos recibido en recipientes insertos en el tiempo, en la historia, en la cultura de hombres determinados. Presentarlos al hombre y la mujer del siglo XXI implica, entonces, reconocerlos necesitados de interpretación y actualización para mantener su capacidad dialogante y comunicadora. Si creemos que el evangelio responde a los intereses y búsquedas más profundas de la humanidad, y que por lo mismo es buena noticia, la traducción de su mensaje a las categorias y códigos de los nuevos imaginarios de los hombres contemporáneos, se hace una urgencia radical de la evangelización (cfr GS n.62).

En efecto, si la Iglesia mantuvo durante siglos un diálogo fluido con la razón, fundamentaimente en su expresión filosófica, como vehiculo de su evangelización, hoy en dia, una justa evangelización que tome en cuenta al hombre y la cultura actuales, debe abrirse a dialogar con las nuevas vertientes por donde corre el pensamiento humano. La evangelización debe ser capaz de tomar en serio los nuevos puntos de referencia que ordenan los imaginarios colectivos del mundo actual y, para ello, debe recurrir a los 
aportes de los diversos saberes que la humanidad domina hoy en dia: la antropologia, la psicología religiosa, la lingüistica, el derecho, la sociologia, la historia -sólo por nombrar algunas de las ciencias sociales-y sin olvidar la inmensa gama del saber adquirido en el último tiempo por las ciencias llamadas exactas o aplicadas, o por aquellas vinculadas a la cibernética. Esto es de una importancia crucial, sobre todo si tenemos en cuenta que nuestra fe se transmite fundamentalmente a través de textos y fórmulas de carácter precientifico que resultan incomprensibles o muy dificiles de aceptar por un hombre cada vez más formado e informado.

De igual modo, el anuncio de la fe no puede hacerse más desde un concepto añejo de verdad metafísica que muy pocos comparten y comprender, sino a partir del reconocimiento del nuevo concepto de verdad presente en la sociedad actual y que va más allá de lo meramente conceptual, como la adecuación del intelecto a la cosa. Cómo ya dijimos, hoy nuestros contemporáneos, distinguen más entre aquello que "tenemos" por verdadero y aquello que "es" verdadero, en una actitud de sospecha permanente que rechaza los totalitarismos ocultos detrás de la pretensión de una pretendida "verdad absoluta". Por ello, si el hombre contemporáneo rechaza el lenguaje doctrinal, pues ve en él una pretensión arbitraria de imposición ideológica, la evangelización debe ser cuidadosa en su manera de anunciar a Jesucristo más allá de la doctrina y del eclesiocentrismo. Anunciar el evangelio de la salvación obrada en Jesucristo no sólo es un derecho sino un deber de la Iglesia, sin embargo, dicho anuncio debe ser lanzado como una palabra fraterna y solidaria con el hombre de hoy. Palabra convencida y convincente, que se ofrece a la razón humana como una posibilidad de respuesta a la búsqueda de sentido y de plenitud.

No se trata, entonces, de renunciar a la fe sino de cambiar la manera y el lenguaje del mensaje. En efecto, la fe tiene algo irrenunciable que decir al hombre pero sin por ello sentirse autorizada a quitarle la palabra a los demás discursos. La fe debe mostrar al hombre el horizonte que se abre para él cuando es contemplado desde Dios y que, por lo mismo, el hombre corre un riesgo mayor encerrándose en sus intereses narcisitas o egocéntricos, que redundan en voluntad ciega de poder, de lucro o de triunfalismo. Sin embargo, para que esa palabra sea escuchada debe levantarse como una palabra fraterna, dialogante, solidaria con el futuro del hombre, de todos los hombres y especialmente de aquellos que son marginados $u$ oprimidos. Presentar nuestra fe en este estilo más cercano a las inquietudes y formas de los hombres y mujeres de hoy nos permitirá dar un testimonio más claro del verdadero rostro filantrópico de Dios y de su proyecto de vida en plenitud para el mundo. A! mismo tiempo, un paradigma evangelizador como éste nos ayudará a dejar atrás la tentación, siempre presente, de manipular o poseer a Dios, especialmente cuando se idolatran las doctrinas y se confunde la mediación con la Realidad que se quiere enunciar y anunciar. 
Otro aspecto fundamental en la búsqueda de un nuevo lenguaje que nos permita hacer del cristianismo un verdadero anuncio de salvación para el hombre de hoy, sobre todo cuando vemos brotar por doquier las reivindicaciones de autonomia e identidad cultural. es avanzar hacia una real inculturacion de la fe en los limites propios de cada cultura. Salir al encuentro del rostro pluricultural de la humanidad, implicará para la Iglesia una verdadera encarnación de la Iglesia en la pluralidad multicolor con que el Espiritu de Dios nos ha bendecido. Una Iglesia que asuma una praxis de inculturación. en consecuencia con la ley de la encarnación y de la acción del Espiritu Santo en medio de los diversos universos culturales, debe avanzar. sin perder su identidad. hacia un nuevo rostro de su organización institucional marcada por la diversidad.

Si la Iglesia no hace este esfuerzo serio por llevar a cabo este "éxodo" que implique para ella despojarse y morir a ciertos cánones, simbolos y prácticas monocuiturales europeas. estará renunciando a encarnarse verdaderamente en una real dimensión católica, concretizada en iglesias particulares, ancladas profundamente en sus categorias culturales locales, según el modelo de la propia encarnación del Hijo de Dios y con la misma valentia que tuvieron los primeros cristianos que salieron al encuentro gozoso de "las gentes de todas las naciones". La vocación de universalidad de la comunidad cristiana no será una realidad salvifica para todos los hombres y todos los pueblos, mientras no realice esta encarnación verdadera en los diversos universos culturales en que esos hombres están inmersos.

En todos estos puntos, me parece que la contribucion del ministerio teológico a este nuevo paradigma evangelizador que se quiere más dialogal y convincente. es de una importancia crucial. El teólogo como hombre de fo: que reconocen la existencia de Dios y su manifestación a los hombres para su salvación, puede y debe contribuir en primer lugar a liberar a Dios mismo de los discursos doctrinales sobre Dios que pretenden domesticarlo; y puede, por otra parte. contribuir a liberar a la comunidad de sus falsas comprensiones de Dios y del hombre. Desde la exigencia de la comunidad de anunciar a sus contemporáneos el designio salvifico universal de Dios. el ministerio del teólogo no es otro que el de acompañar a la comunidad tanto en su búsqueda de fidelidad al seguimiento de Cristo como en su empeño por llevar a los hombres a una comprensión cada vez mayor de ese misterio insondable de amor filantrópico.

\section{Evangelizar desde una Renovada Opción por los Pobres}

Es un hecho que la sociedad global que se va construyendo, resulta ser más bien una sociedad "dual" que ampara un proceso de marginación radical de al menos un quinto de la humanidad, las que hoy en el mundo sufren la exclusion y mueren sin siquiera llegar a ser noticia en los Medios de Comunicación Social. No se trata de cifras sino de personas con rostros concretos: ancianos. adultos, jóvenes y niños, golpeados por la falta de los minimos necesarios para vivir dignamente (DP 31-40). Hombres y mujeres 
sufrientes, victimas de la injusticia de un sistema que los explota o, en el peor de los casos, los margina y los olvida No son cifras, sino hermanos nuestros que claman al cielo por su liberación (DM, Justicia, 1), y cuya presencia deberia golpear nuestra conciencia, indignarnos éticamente y movernos "a aceptar y asumir la causa de los pobres... como si fuera la causa misma de Cristo" (cfr DP. Mensaje, 3).

Desgraciadamente, la pobreza sigue siendo una cuestión estructural que por lo mismo requiere para su solución un proyecto de sociedad alternativo al actual sistema global de libre mercado, claramente injusto y excluyente. Por ello, anunciar hoy en dia la salvación de Jesucristo debe hacerse desde el horizonte de la liberación de los pobres. Frente a la indiferencia sobre la suerte de los pobres, la evangelización no puede perder de vista la solidaridad. Según el Concilio, el camino que conduce a la justicia en el mundo pasa por un cambio de horizonte ético, en donde el individualismo queda superado por la solidaridad (cfr GS n.30). En este sentido, anunciar hoy la salvación, puede y debe ser traducido por anunciar la igual dignidad que todo hombre posee y cuya defensa se impone a la sociedad como una obligación de justicia. El compromiso solidario no debe entenderse como una mera y fácil acción asistencialista, sino que nos abre al compromiso politico que tiende a la creación de estructuras sociales que reflejen las relaciones sociales de participación y comunión. En consecuencia, el compromiso social de los cristianos, asi como de todos los hombres de buena voluntad, debe tener como horizonte el que las estructuras sociales, especialmente las económicas, estén al servicio de esa dignidad que todo hombre y mujer posee de modo inalienable (cfr GS n.29).

Hoy en dia, en un mundo marcado por la idolatria de la propiedad privada y del lucro, anunciar el Evangelio debe hacerse desde la conciencia, tradicional en la doctrina social, de la propiedad común de los bienes pues, mientras no existan canales adecuados que permitan y obliguen a la redistribución de la riqueza será muy dificil la superación de esta injusticia radical de nuestra sociedad contemporánea. La Propiedad Común de los bienes es propiamente de origen divino y, por lo tanto, anterior a la propiedad privada que es de origen social, y cuya finalidad no es otra que velar por que se cumpla el orden querido por Dios, es decir, que todos tengan lo que necesitan para alcanzar su desarrollo pleno como seres humanos(cfr ST, II-II, q.66). La propiedad de los bienes es un derecho natural de todo ser que llega a este mundo. Su privación es injusticia y pecado. O sea, la propiedad privada sólo puede ser aceptada en cuanto contribuye a que todos accedan a los bienes necesarios para desarrollarse humanamente (cfr GS 69). En consecuencia, cuando asistimos al espectáculo grotesco de la acumulación del capital en muy pocas manos, la evangelización no puede renunciar a su compromiso con liberación de los pobres.

Me parece, para concluir este punto, que la Iglesia en su rol evangelizador debe ser capaz de generar un movimiento formativo en vistas 
a la acción politica práctica de los que nos llamamos cristianos, sin excluir, por supuesto, a todos aquellos hombres y mujeres que comparten con nosotros los mismos anhelos de justicia y solidaridad. Se trata de asumir una práctica formativa y efectiva en favor de los pobres teniendo como horizonte la utopia del Reino, es decir, el deseo de Dios de ver a todo hombre y a toda mujer viviendo en plenitud. Se trata de generar desde la base una práctica participativa y solidaria que tenga a los pobres como protagonistas, como sujetos y no como objetos, de tal modo que se evite toda forma de paternalismo ya sea económico (de los "tecnócratas") o político (de las llamadas "vanguardias conductoras"), asi como la manipulación ideológica o religiosa de los pobres.

Un proceso formativo al interior de las comunidades cristianas que lleve a superar el inmobilismo o la indiferencia de muchos cristianos por la cosa política asi como la superación de las soluciones de corte meramente asistencialista, para concentrarse en la búsqueda de una verdadera "caridad politica" o "santidad politica" que no pierda de vista el horizonte estructural de la situación actual y que, por lo mismo, deberia apuntar a la generación de comunidades cristianas adultas, comprometidas proféticamente con la superación de la pobreza y la marginación en vistas a la realización aqui y ahora del reino de Dios, que es vida en abundancia para todos.

\section{Evangelización y Valorización de las Otras Experiencias Religiosas}

Gracias a la globalización de la información que se da por el amplio acceso a los medios de comunicación, es muy difícil para cualquier adepto de una religión, incluida la Católica, ignorar las otras manifestaciones religiosas presentes en el mundo o arrogarse, sin más, un status de mediación única y necesaria para la salvación universal. Los oidos contemporáneos no están dispuestos a soportar una tal pretensión. Por lo mismo la evangelización correria un gran riesgo si nuestro anuncio de la salvación universal se confundiera con la pretensión "arbitraria" de una religión por imponerse como único camino para toda la humanidad. En este sentido aboga la Declaración Sobre la Libertad Religiosa del Concilio cuando rechaza toda forma de coacción sobre las conciencias de los hombres (nn.1.2.4) e incluso, opta por evitar la identificación de la "única religión", es decir, la única voluntad salvífica universal de Dios, con la "Iglesia católica y apostólica". Cierto aquella "subsiste" en ésta, pero no se les identifica, lo cual habria equivalido a la utilización del verbo "ser", que los padres conciliares excluyeron deliberadamente (DH n.1; cfr LG n.8.16; UR n.4; NA n.1).

Como lo demuestra la historia de las religiones, la apuesta creyente sobre la existencia de Dios no implica necesariamente una confesión única de Dios. Muy por el contrario, por una dinámica propia de la pluralidad cultural, la confesión de Dios conlleva una inmensa gama de nombres de Dios, todos con más o menos pretensión de universalidad, pero sin que uno 
de ellos logre agotar el discurso sobre Dios. Por lo mismo, la evangelización católica debe evitar el riesgo del solipsismo encerrándose, de modo autorreferente, al diálogo interreligioso y rechazando a priori la posibilidad de enriquecerse con las diversas perspectivas sobre Dios y sobre el hombre que cada pueblo ha ido decantando a través de su historia. La búsqueda de Dios es una aventura que hacemos como humanidad entera, en donde hombres y mujeres santos nos ayudan, desde sus capacidades personales y culturales, a encontrarnos con esa experiencia fontal que se nos transparenta cotidianamente, pero a cuya manifestación y cercanía no siempre somos suficientemente sensibles.

"El agua, al caer en un vaso vacio, gargarea; mas, si el vaso esta lleno, no se oye ruido alguno. De igual manera, el hombre que no haya descubierto a Dios está siempre discutiendo inútilmente sobre su esencia y su existencia, mientras que el que to haya experimentado goza en silencio de la felicidad divina... Lo mismo que la sustancia única agua es llamada con diferentes nombres por los distintos pueblos -unos la llaman 'water; otros, 'vari'; éstos, 'acqua'; aquéllos, 'pani'- asi al único Saccidananda le invocan unos como Dios, otros como Allah, aquéllos como Hari, éstos como Brahman... Las diferentes religiones no son más que caminos diversos para alcanzar al único Dios. Diferentes son las vias que llevan al templo de la Madre Kali de Kalighat, en Calcuta. Asi también son diversas las vias que encaminan al hombre a la casa del Señor. Toda religión no es nada más que una de esas vias... A causa de su ignorancia, la gente corriente piensa que su religión es la mejor de todas, y por eso hace inútilmente tanto ruido. En cambio, cuando su mente esté iluminada por la sabiduria verdadera, toda lucha sectaria cesará"t

En acuerdo con la hermosa expresión de este mistico, Dios existe independientemente de los nombres que se le den, pues él no depende de las fórmulas, que no son otra cosa que construcciones intelectuales humanas, de modo que la verdad total sobre Dios nunca la poseeremos pues, por definición, Dios sobrepasa todas nuestras espectativas. Si los hombres hemos hecho "doctrinas" sobre Dios, él pre-existe y está más allá de ellas. Las fórmulas y doctrinas permanecen sólo como andamiajes, más - menos apropiados, para acercarnos a él. Hasta podriamos decir que el equivoco sobre Dios cruza todas las religiones, pues ninguna de ellas es capaz de aprehenderlo en su totalidad, sin por ello negarles sus aciertos y sus intentos por conocerlo y amarlo.

Esto nos libera del totalitarismo fanático que suele impregnar a ciertos representantes de las religiones, y nos impulsa al reconocimiento del otro

Ramakrishna, citado en: D. ACHARUPARAMBIL, Espiritualidad Hinduista, BAC, Madrid 1982, p. 233s. 
como un compañero en el camino que hace toda la humanidad hacia Dios. Profundizando según el espiritu de la Declaración Nostra Aetate del Vaticano II (cfr n.2) no podemos descalificar sin más ninguna religión, ni tampoco sentir que sólo a nosotros, católicos, se nos ha revelado Dios. No se postula aqui un relativismo religioso, "toda religión da lo mismo", sino la necesidad de dialogar con los demás en busca de categorias que nos proporcionen una cada vez mayor comprensión del misterio de Dios, basada en la firme convicción que ese Dios "no es sólo Padre de los cristianos sino de todos por la creacion" (Origenes) y que, por io mismo, se manifiesta a sus hijos por caminos que sólo él conoce, pero que en ningún caso los priva de su amor y de su cercania.

Existen algunas constantes que nos permiten pesar la pertinencia de tas imágenes de Dios y de las prácticas religiosas subsecuentes que se vehiculan en las diversas religiones. Una de ellas, y fundamental, es que Dios no es un "rival" del hombre y que, por lo mismo, su acción en el mundo apunta a la vida en plenitud de sus hijos. En consecuencia, sólo será verdadera una religión que pase por el "amor al prójimo" como vehiculo del encuentro y de la manifestación de la divinidad, pues, sólo esa actitud puede ser sacramento real, universal y transcultural de Dios. La fraternidad universal que propugnan las religiones es una realidad que va mucho más allá de un solo anhelo de sociedad, es la manifestación definitiva, escatológica, de la existencia de Dios Trinidad y de la realización de su Único Designio salvifico para la humanidad entera?.

Esta referencia esencial, que no es patrimonio sólo de los que nos confesamos cristianos, será siempre el norte de discriminación que oriente todo diálogo entre las religiones y de cada religión consigo misma, pues, el riesgo de desvirtuarse está siempre presente. Cualquier religión que apunte a la muerte y no a la vida, se equivoca tanto en su experiencia de Dios como en el Dios que dice servir. Aqui se encuentra la importancia de una necesaria y constante critica de nuestras imágenes de Dios que confesamos; pues, de alguna manera, todos cuando decimos Dios damos un contenido semántico a esa palabra que brota de nuestras propias experiencias, gratas o ingratas, que, querámoslo o no, siempre nos condicionan. Muchas veces, el Dios que adoramos o rechazamos son nuestros propios fantasmas y no el Dios verdadero que se nos reveló como un posibilitador de nuestros deseos más hermosos.

Pero digamos algo más. Si hasta aqui afirmamos que todos estos caminos conducen al encuentro con Dios, tambièn queremos afirmar que en el cristianismo se alcanzan dimensiones sorprendentes para la comprensión humana. En efecto, en el cristianismo, este encuentro se realiza en la humanización misma de Dios, más aun, en el anonadamiento extremo de un

En csta perspectiva, los cncuentros interreligiosos que el Papa Juan Pablo II ha convocado en la Porciúncula, adquieren una dimension profética y sacramental impresionante, que abre horizontes, hasta hace un tiempo, imposibles de imaginar. 
Dios hecho hombre pobre, marginal y crucificado. Ya no se habla de Dios, sino que Dios habla con nosotros en nuestra propia historia y condición. Si bien esta idea de encarnación no es nueva en la historia de las religiones -en la tradición bhakti del Hinduismo, por ejemplo, se postulan múltiples encarnaciones (avatara) de la divinidad, incluso algunas en realidades subhumanas, con una finalidad salvifica ${ }^{3}$-, en el cristianismo dicha encarnación deja de ser una simple manifestación de la divinidad para convertirse en el anuncio capital del anonadamiento de Dios mismo, que se hace semejante a nosotros con la asunción en sentido pleno de nuestra naturaleza. Esto que resulta, por decir lo menos, transgresor de nuestras categorias, se encuentra en el centro de la fe cristiana: el Dios hecho hombre y hombre crucificado, "escándalo para los judios y necedad para los gentiles" (1Cor $1,23)$.

Por lo mismo y en cierto modo, los cristianos podemos decir que no creemos "en Dios", en el sentido de la creencia en un "ser" divino sin rostro, sino "en el Dios que se nos manifestó en Jesucristo", es decir, en un Dios con figura humana, manifestado él mismo para nuestra salvación; y no sólo en una proyección intelectual pertinente al momento de otorgar un sentido al Cosmos y al ser humano pero, en el extremo, no más que una posible creación de nuestro intelecto y hasta de nuestros temores. De alli, la importancia de acercarnos al testimonio que nos ha llegado a través de las Escrituras, con la debida honestidad intelectual, que nos permita acceder lo más justamente posible a dicha realidad fontal, genial y sorprendente.

\section{Como los Discípulos de Emaús, hacer caer NUESTRAS VENDAS}

Como anunciabamos al introducir este escrito, un segundo objetivo que pretendemos con estas reflexiones es hacer una invitación a adoptar una actitud más abierta, más universal y tolerante desde la cual confesar nuestra fe en un mundo lleno de novedades y desafios. Se trata de alentar a las comunidades cristianas a evangelizar desde su coherencia práctica con el Evangelio que anunciamos, esto es evangelizar desde el testimonio o desde la ortopraxis cristiana.

Nos pareció interesante, por la genialidad del relato, iluminar esta nueva dinámica evangelizadora desde la lectura atenta de Lc 24, 13-35, que es un texto muy conocido pero no suficientemente profundizado en su significado para la práctica cristiana. En efecto, el relato de los discípulos de Emaús nos sitúa en el horizonte del discipulado, con todo lo que ello tiene de crisis y de renuncia a nuestras propias esperanzas nacionalistas o narcisitas que pueden impregnar la vida de la comunidad e impedirnos reconocer a 
Jesús y acoger con gozo el Designio Salvifico universal que se nos manifestó en su aparente fracaso.

\section{Lectura del Relato}

Primero que nada, recordemos que en el evangelio de Lucas todos los acontecimientos que rodean la resurrección de Jesús y su ascensión tiene lugar en un solo domingo, "el primer dia de la semana" $(24,1)$. Incluso en él, contrariamente a to que se indica en Hch 1, 3. no hay ningún indicio que el resucitado se hubiese aparecido a los discipulos durante un periodo de cuarenta dias. Por otra parte, en clara discordancia con Mateo que coloca la aparición de Jesús a sus discípulos en Galilea (28,7.16-20). Lucas sitúa en Jerusalén y sus alrededores todos estos acontecimientos: Emaús y Betania $(24,50)$ o el monte de los Olivos (Hch 1,12) para la ascensión. Esto no es casual, sino que obedece a la intención deliberada del autor de traer a la mente del lector el primer dia de la creación; es decir, de darnos una clave de lectura para los acontecimientos que se nos narran. En este caso: que con la resurrección comienza una nueva creación que es definitiva y que alcanza a todo hombre. La muerte ha sido vencida y se ha hecho realidad el Designio Creador de Dios.

E) evangelista estructura el episodio en torno a cuatro escenas claramente distinguibles, a través de las cuales accedemos a la profunda crisis que vivieron los discipulos de Jesús. Ellos, que habian puestos sus espectativas mesiánicas en Jesús, no han sido capaces de ver en su muerte "la gloria del Mesias" porque no estaban dispuestos a renunciar a sus esperanzas nacionalistas. Una vez superada su ideología reconocen al Resucitado y se convierten en heraldos de la Voluntad Salvifica de Dios que se ha manifestado en el triunfo de Jesús sobre la muerte.

\section{a) Vv.13-24: Ios discipulos interpretan los acontecimientos desde sus categorias nacionalistas: "Ia gloria de Israel"}

Los dos discipulos pertenecen al circulo descrito en 24,9.11, que no están dispuestos a aceptar el testimonio de las mujeres $(23,55-24,11$. 2224).

Se dirigen a Emaús, una aldea fortificada a $30 \mathrm{~km}$ al noroeste de Jerusalén, en la que aun permanece vivo el recuerdo del triunfo obtenido 160 años antes por Judas Macabeo sobre los enemigos de Israel, que murieron en número de tres mil ( $1 \mathrm{Mac} 4,1-26$ ) y que fundamenta la esperanza del triunfo futuro del Mesias. Asi, esta referencia geográfica del evangelista resulta muy clarificadora sobre la identidad de los protagonistas: son discipulos imbuidos de las esperanzas mesianicas nacionalistas judias por ello se dirigen a Emaus la ciudad del triunfo sobre los enemigos de Israel-.

El que salgan de Jerusalén no indica en ellos, como si lo es en los demás evangelios, una ruptura o un proceso de distanciamiento de 
Jerusalén, centro del nacionalismo Judio -recordemos que alli están el Templo y el Sanedrin- y, por 10 mismo, de su influencia, sino que permanecen en su órbita (el sentido de la palabra "aldea", como veremos más adelante). El tema de conversación son los acontecimientos en torno a la muerte/fracaso de Jesús (14).

Jesús en persona se acerca y se pone a caminar con ellos (15), pero no lo reconocen pues sus ojos están incapacitados para ello, pues algo les impide ver, están como vendados (16). El tema de la "ceguera" es recurrente en Lucas (cfr 8,$10 ; 9,45 ; 19,42 ; 18,35-38$ : este último episodio es de gran virtualidad pues el ciego lo proclama "Hijo de David" que es el titulo que expresa la esperanza nacionalista judia de un Mesias que daria el triunfo a Israel sobre sus enemigos llevándola a la gloria). En efecto, sus ojos están como ciegos para reconocer el triunfo de Jesús, para ellos él está total y definitivamente muerto: "ya van tres dias de su muerte" (21b)

Cuando Jesús les pregunta de qué están hablando, se detienen entristecidos: su relato confirma su pena por la muerte de Jesús, pero sobre todo por la frustración de su esperanza mesiánica que habian depositado en él (17). Cleofás, uno de los discipulos que sólo por esta vez aparece en los evangelios, toma la palabra y narra el motivo de su tristeza (18). Aun siendo discípulos cercanos tienen la misma percepción del pueblo $(7,16 ; 9,8.19)$ : para ellos Jesús era sólo un profeta (19). Son incapaces de comprender el triunfo de Jesús y de reconocerlo como el Mesias porque siguen bajo la influencia de las instituciones judias: "nuestros jefes" (20).

Como se dijo, esperaban que Jesús fuera el Mesias liberador de Israel (21), al estilo de la esperanza mesiánica nacionalista (cfr 1,68s). No están dispuestos a reconocer a Jesús como Mesias universal $(2,30-32)$, muerto y crucificado (cfr 9,22.44S; 18,32-34). Esperaban que él los condujera al triunfo sobre los enemigos de Israel, y ni siquiera los indicios de su resurrección -el testimonio de las mujeres y el sepulcro vacio- los hace cambiar de actitud.

\section{b) Vv. 25-27: Jesús interpreta su mesianismo desde el proyecto de Dios: "Ia gloria del Mesias"}

El reproche de Jesús a su torpeza y a su lentitud para creer (25), apunta a su incapacidad de caer en la cuenta que la "gloria" del Mesias, su verificación como tal, está precisamente en el ser rechazado por la sociedad injusta y sus representantes (20).

Es en esta ruptura del Mesias con las instituciones injustas de Israel, que se manifiesta la acción liberadora de Jesús. El pone en marcha el nuevo éxodo del pueblo hacia la vida definitiva. Israel ha llegado a ser la verdadera tierra de esclavitud y muerte, de la que el Mesias nos llama a salir, hacia la solidaridad universal y el verdadero triunfo de la vida sobre la muerte, esa es su "gloria": hacer realidad el designio creador de su Padre (26). Tal era la promesa contenida en el Antiguo testamento (27). 
Sin embargo. Ios discipulos continuan aferrados a las esperanzas nacionalistas judias. No han logrado darse cuenta que la teologia oficial del triunfo nacionalista del Mesias era falsa (cfr 19.30; 20.41-44), porque falseaba a Dios y su proyecto para la humanidad.

\section{c) Vv.28-32: los discipulos pasan de la incomprension/ceguera a la comprensión/visión. Reconocen/ven al Señor}

En una actitud distinta a la de los discipulos cuya meta es Emaús, Jesús continúa su camino (28), sólo la invitación de los discipulos lo detiene. Son "ellos" la razón de estancia en la "aldea" no su adhesión a la ideologia nacionalista judia de los discípulos. Recordemos que la "aldea" hace referencia a una ciudad bajo la órbita de influencia de Jerusalén, por lo cual, el gesto de Jesús deja en claro a los discipulos su ruptura con la ideologia de las instituciones judias (29).

Con el gesto de la fracción del pan (30), que no está primeramente en relación directa con la eucaristia $(22,19)$ sino con el episodio de los panes (9,12-17: bendición del pan, no acción de gracias), Jesús les vuelve a dar la señal que los llevó en otro momento a su reconocimiento como Mesias $(9,18-20)$. Jesús les enseña asi que la entrega y el don de si mismo, significados en el pan compartido, son el signo de su mesianismo. Sólo entonces se abren sus ojos (cfr Is 35.5: metáfora de liberación) pues era la doctrina mesiánica que habian internalizado por su formación judia, el obstáculo que les impedia ver/reconocer al verdadero Mesias (31a).

Acto seguido Jesús desaparece a sus ojos, su presencia ya no pasa por la verificación de los sentidos, como lo era antes, sino que ella está oculta pero cierta (31b). Los Hechos de los Apóstoles dirán que "una nube le ocultó a sus ojos" (1.9), es decir, desde su resurrección Jesús, el nuevo y definitivo Mesias, estará acompañando a sus discipulos de igual modo que Yahvéh lo hizo con Israel en el desierto (Ex 13,21-22).

Luego de un proceso de tensión interior ("estabamos en ascuas" o "nuestro corazón ardia". 32), es decir, lucgo de un proceso doloroso y trabajoso de ruptura con sus antiguas esperanzas mesiánicas, los discipulos por fin se han liberado de su ceguera y están preparados para emprender el camino del verdadero éxodo.

\section{d) Vv. 33-35: Regreso a Jerusalén y reencuentro con la comunidad creyente.}

Se levantan (33), es decir, se realiza en ellos la obra del Mesias, recuperan su libertad y su capacidad de actuar, alcanzando la vida plena. Aqui es de gran significado el verbo levantarse presente reiteradas veces a través de todo el evangelio en los más diversos episodios: el de la suegra de Pedro $(4,39)$, del paralítico $(5,23-25)$, del hombre de la mano seca $(6,8)$, del hijo de la viuda de Naim $(7,14)$, de la hija de Jairo $(8,54)$, del leproso $(17,19)$. Significativamente, Jesus es acusado de "soliviantar al pueblo" (23.5), y él 
mismo "se levanta" de la muerte at tercer dia $(24,7)$. La misma expresión aparece repetidas veces en el Libro de los Hechos $(3.6 ; 8.26$; 9.11. 34. 40; $12,7 ; 14,10)$.

El resultado de su acción de levantarse es el reencuentro con los once y los demás discipulos testimoniando el "triunfo del Justo". Les confirman que Simón -no Pedro, que es el apodo que Jesús le habia dado por su obstinación (cfr 22,62: el llanto de Pedro)- vió también al Señor resucitado (34). Hecho que, por lo demás, no está consignado en ninguna otra parte del evangelio. En el v. 35, se repite la idea que reconocieron a Jesús en la "fracción del pan". es decir, en su entrega que ahora debe ser continuada por los discipulos y cuyo memorial permanente será la eucaristia.

\section{Actualización: Preguntas para la praxis contemporánea de la Iglesia ${ }^{4}$}

De la lectura global que acabamos de hacer del texto de Lucas se abren una serie de preguntas para un proceso de reflexión sobre el estado actual y las perspectivas que podemos esperar de la evangelización. En efecto, el texto va de un modo muy pedagógico llevándonos a una actitud de autocritica y señalándonos ciertos hitos para una adecuación de la vida eclesial en correcta correspondencia con la fe que queremos anunciar a nuestros hermanos. Hagamos algo de ese ejercicio:

v.13. "iban dos de ellos a un pueblo llamado Emaús": ¿Cuál es nuestra meta? ¿Hacia donde vamos? ¿Es la meta que el Señor quiere, o es la de nuestros intereses egoistas o meramente institucionales?

v.14. "conversaban entre si sobre lo que habia pasado": ¿Cuáles son los acontecimientos que marcan el mundo de hoy? ¿Nuestras comunidades están abiertas a los signos de los tiempos? ¿Somos capaces de ver lo bueno que hay en el mundo?

En la XIV Asamblea General de la Conferencia Latinoamericana de Religiosos (CLAR), de junin del año 2000 , se propuso a la Vida Religiosa del continente entrar en un periodo de "refundacion" de la misma bajo el lema. "Por el camino de Emaús". Con ello se pretende en medio del momento actual que vive el continente y en un lapso de tres años, jalonado en tres etapas: año 2001. "La memoria desde el presente": año 2002: "Los desafios del contexto latinoamericano": y. año 2003: "Proyecciones y prospectivas de refundación". profundizar tas cinco lineas inspiradoras de la CLAR, es decir: "la renovada opción por los pobres, la opcion por los jovenes. la mujer y to femenino. la espiritualidad encarnada, incuiturada y libcradora y hit nueva ectesialidad". El objetivo de entrar en este kairos es, on definitiva. "impulsar uma vida religiosa que viva en fidelidad creativa su respuesta hoy a esta sociedad quo crea cada dia mas excluidos y se convierte en una sociedad deshumamizadora. sin consideracion a los derechos humanos y de ka creación". En este marco. se me pidio una jornada de formación para la CONFERRE de la IX Región, la que da origen a esta parte del articulo. 
v.16 "sus ojos estaban obstaculizados para reconocerlo": ¿Qué nos impide reconocer hoy a Jesús? ¿Cuál es nuestra imagen mesiánica de Jesús? ¿Cuáles son nuestros intereses, son los del Señor?

v.20. "le condenaron a muerte y lo crucificaron": ¿Estamos dispuestos a jugarnos por entero por el Reino? ¿Estamos dispuestos a perder el prestigio, el poder, la vida? ¿Estamos dispuestos a ser rechazados por las autoridades eclesiásticas y sociales?

v.21a. "nosotros esperábamos que el glorificaria a /sracf": ¿Cuáles son hoy nuestras preocupaciones? ¿Cuáles son los temas de nuestra evangelización? ¿Cuales son nuestras esperanzas? ¿Son evangélicas, es decir, son una buena noticia para los pobres y marginados? ¿Están en relación con el proyecto filantropico de Dios?

v.21b. "Hevamos ya tres dias desde que esto paso": ¿Cuáles son nuestras tristezas, nuestras frustraciones? ¿Son narcisistas o evangélicas?

v.27a. "continuando por los profetas": ¿Cómo los profetas hemos escudriñado los tiempos buscando la voluntad de Dios? ¿Hemos escuchado a los profetas, los de ayer y de hoy? ¿Es nuestra vida verdaderamente profética?

v.27b. "les explicó las Escrituras": ¿Conocemos las Escrituras? ¿Nos hemos renovado en nuestra formación teológica o tenemos una fe ingenua e infantil? ¿Estamos al tanto de los nuevos conocimientos y su aporte a una espiritualidad más evangélica?

v.29. "quedate con nosotros...": ¿Nuestras comunidades son fortalezas o lugar de acogida y encuentro fraterno? ¿Nuestra vida cotidiana, nuestra mesa está abierta al peregrino? ¿Nuestras comunidades son ecuménicas y macro-ecuménicas?

v.30. "tomó el pan, pronunció la bendicion. to partió y se los iba dando": ¿En qué hemos fundado nuestra espiritualidad en estos años? ¿Partir el pan sigue siendo significativo para nosotros?

v.32. "no cstaba ardiendo nuestro corazon": ¿Qué cambios estamos dispuestos a asumir? ¿Seremos capaces de renunciar a lo accesorio para quedarnos con lo que es verdaderamente fundamental? ¿Nuestras instituciones están dispuestas para servir y acoger a los pobres?

v.33. "y levantandose al momento": ¿Estamos dispuestos a hacer del Proyecto de Dios nuestro proyecto? ¿Somos capaces de dar testimonio de la vida entregándonos como Jesús? ¿Tenemos aun ganas de vivir el Evangelio?

\section{Conclusión}


La evangelización en el momento actual que vive la humanidad y en el momento que vive nuestra propia Iglesia requiere refundarse en el seguimiento de Jesús desde una espiritualidad capaz de distinguir entre nuestros deseos personales e institucionales y el deseo de Dios para el mundo. Una espiritualidad de mas Evangelio y menos narcisismo tanto personal como institucional. Una evangelización fundada en una espiritualidad del discipulado atento al Designio de Dios y cuyo "culto" sea el testimonio de una solidaridad organizada al servicio del Reino, comprometida con la justicia, especialmente a favor de los pobres y en una acción profética de denuncia de las estructuras sociales y eclesiales cuando ellas no son coherentes con la proclamación del Evangelio de la vida en plenitud (cfr Jn 10,10).

Esto es crecer hacia una espiritualidad que nos aleje de la tentación "nacionalista", la misma que llevó a las autoridades judias a no reconocer a Jesús como el Mesias de Dios, e impida a la Iglesia erigirse como centro de la historia de salvación y en punto de referencia único para el encuentro con Dios. Si no somos capaces de vencer esta tentación narcisista. la Iglesia se verá cada vez más incomunicada con el mundo $y$, en particuiar, con el mundo de los pobres, de la mujer, de los jóvenes. de los obreros, de los pueblos indigenas. etc. Incapaz de aprehender y reconocer alli la presencia del Reino. que crece por la fuerza del Espiritu aun antes de la llegada del misionero. Se trata de invertir nuestra mirada para creer que en el mundo, en medio de sus complejos procesos, se va haciendo realidad. poco a poco. el futuro escatológico de toda la humanidad. Debemos ser capaces de reconocer la bondad presente en los demás, más allá de las fronteras de nuestras comunidades, de nuestros sacramentos. para ver que no estamos solos en este empeño por ayudar al parto de un mundo nuevo (cfr Mc 13,8).

Nuestra fe antes que ser un gran discurso intelectual sobre Dios, el hombre y el cosmos. es una gran invitación al amor. a la solidaridad con los pobres, a la espera atenta y activa de la realización definitiva del proyecto filantrópico de Dios, que es hacernos entrar, a todos, en su comunión eterna de amor. La evangelización más que una palabra dirigida al intelecto y a los intelectuales, debe ser una "buena noticia" dirigida a los pobres. a los que no cuentan a los ojos del mundo, a los ignorantes y a los cansados por el peso de las injusticias y los sufrimientos. Nuestra fe no es para permanecer encerrados en una biblioteca -aunque algunos debamos hacerlo como un servicio para el bien de todo el cuerpo-, sino un salir al encuentro de los gozos y las esperanzas, de las penas y las angustias de los hombres y mujeres, nuestros hermanos para alentarlos en este camino hacia la felicidad total.

Sólo anunciaremos correctamente nuestra fe. como una buena noticia de vida en abundancia para todos los hombres y mujeres que Dios ama con igual solicitud de Padre, cuando nuestra praxis sea coherente con aquel que es "el camino verdadero que conduce a la vida" (Jn 14.6). 